RESEARCH ARTICLE

\title{
Effect of the Peripheral Trpm8 Ion Channel Activation on the Cardiovascular Parameters
}

\author{
TV Kozyreva ${ }^{1,2 *}$ VP Kozaruk ${ }^{1}$ and ES Meyta ${ }^{1}$ \\ ${ }^{1}$ Institute of Physiology and Basic Medicine, Russia \\ ${ }^{2}$ Novosibirsk State University, Russia
}

*Corresponding author: TV Kozyreva, Institute of Physiology and Basic Medicine, Timakov street 4, Novosibirsk, 630117; Novosibirsk State University, Novosibirsk, Pirogov street 2, Novosibirsk, 630090, Russia

\begin{abstract}
The role of TRP ion channels in the physiological processes is far from clear. In this work we studied the effect of the activation of the peripheral TRPM8 ion channel by its agonist menthol on the cardiovascular parameters in normotensive and hypertensive rats when animals were coming out of anesthesia. The role of the TRPM8 ion channel in the regulation of blood pressure was clearly seen in normotensive animals: Activation of this channel by application of $1 \%$ menthol (agonist of TRPM8 ion channel) to skin significantly accelerated the increase in blood pressure and recovery of heart rate when animals come out of anesthesia. The mean rate of pressure rise increased 3 times under the menthol. In hypertensive animals there was weaker and short-time increase in the rate of arterial pressure rise under menthol. Lower sensitivity of hypertensives to menthol is consistent with our previous data on the two fold decrease in the expression of Trpm8 gene in these animals. Recent results evidence that the TRPM8 ion channel is involved in the regulation of blood pressure and this depends on the level of the Trpm8 gene expression. A decrease in the expression of the Trpm8 gene in hypertensives can be a compensatory protection.
\end{abstract}

\section{Keywords}

TRPM8 ion channel, Arterial pressure, Blood volume, Hypertension, Normotension

\section{Introduction}

We have previously shown that in hypothalamus (a structure responsible for the regulation of many visceral functions) of rats with hereditary stress-induced arterial hypertension, the expression of the gene encoding the cold-sensitive ion channel TRPM8 is reduced [1].
Very little is known about the role of this ion channel in forming the characteristics of the cardiovascular system, and the information that is available in literature is ambiguous and contradictory. Thus, some works [24] state that the introduction of menthol (an agonist of the TRPM8 ion channel) to the skin of forearm area causes vasodilation of skin vessels and an increase in blood flow. There are data $[5,6]$ which show weakening of the pressor response to muscle load under the influence of menthol and menthol-containing ointments. The authors, however, note the short duration of this effect. On the other hand, [7] notes a decrease in vascular conductivity under the influence of both menthol and cold, i.e. under the influence of both temperature and non-temperature activation of the cold-sensitive peripheral TRPM8 ion channel. Thus, the question of the effect of activation of this ion channel on the parameters of the cardiovascular system and especially blood pressure remains open. The change in the level of gene expression of the TRPM8 ion channel in rats with hereditary arterial hypertension primarily raises the question on the connection of this ion channel with the work of the cardiovascular system and arterial pressure.

The search for drugs that allow to correct blood pressure and other parameters of the cardiovascular system in the process of getting out of narcosis are of particular interest for medicine. Considering TRP ion channels as a therapeutic target, it is important to understand whether their activation can affect the parameters of the cardiovascular system.

Citation: Kozyreva TV, Kozaruk VP, Meyta ES (2019) Effect of the Peripheral Trpm8 Ion Channel Activation on the Cardiovascular Parameters. Int Arch Clin Pharmacol 5:019. doi.org/10.23937/25723987.1510019

Accepted: July 04, 2019: Published: July 06, 2019

Copyright: (c) 2019 Kozyreva TV, et al. This is an open-access article distributed under the terms of the Creative Commons Attribution License, which permits unrestricted use, distribution, and reproduction in any medium, provided the original author and source are credited. 
The purpose of this study is to evaluate the effect of the activation of the peripheral TRPM 8 ion channel by its agonist menthol on the parameters of the cardiovascular system in normotensive and hypertensive rats when animals are coming out of anesthesia.

The tasks of this study were to find out the following:

1) How the parameters of the cardiovascular system change under anesthesia in normal and hypertensive rats.

2) Compare the parameters of the cardiovascular system at coming out of anesthesia in normal and hypertensive animals.

3) Find out how the activation of the peripheral TRPM8 ion channel (by its agonist menthol) affects the functioning of the cardiovascular system upon coming out of anesthesia in normal and hypertensive animals with different levels of the TRPM8 ion channel gene expression.

\section{Methods}

\section{Animals}

In the experiments male rats of two lines were used: Hypertensive rats of the HSIAH line (hereditary stressinduced arterial hypertension [8], and normotensive Wistar rats; weighing 300-340 g. The animals were housed at ambient temperature $22-24{ }^{\circ} \mathrm{C}$, natural darklight cycle with free access to water and food (special food for laboratory animals - 'Chara', "Assortiment AGRO", Russia). The experimental procedures were carried out in compliance with the Directive 2010/63/ EU of the European Parliament and of the Council of 22 September 2010, its correction of 20 December 2013 (2014/63/EU) and approved by the ethic committee of the Institute of Physiology and Fundamental Medicine. The course of the experiment is shown in (Figure 1).

\section{Application of substances}

$1 \%$ suspension of menthol (L-menthol, Sigma) in distilled water was applied in thermoneutral conditions to skin. It is well known that there are a lot of sensory fibers in skin which express temperature sensitive TRP ion channels including the cold-sensitive TRPM 8 ion channel [9-11]. In control animals distilled water application was conducted. The application was carried out on the skin of the abdomen, which was previously freed of hair; the area of application was $25 \mathrm{~cm}^{2}$, time of application - 20 minutes. The application of substances was done to anesthetized animals (Nembutal $50 \mathrm{mg}$ / $\mathrm{kg}$ ), since it took a certain time for animals to remain immobile without emotional stress. During the application, the anesthetized animal was on a panel controlling temperature so that the skin temperature was $32.9 \pm$ $0.25^{\circ} \mathrm{C}$, and the rectal temperature $-38.2 \pm 0.15^{\circ} \mathrm{C}$.

The parameters of the cardiovascular system were measured in animals while being awake (before anesthesia), under anesthesia and when recovering from anesthesia. Parameters were measured by a non-invasive method using the Coda system ("Kent Scientific", USA) according to the order shown in Figure 1. When measuring parameters, animals were in plastic transparent cones with tails out. Two cuffs were placed on the tail. To reduce the emotional component, as well as to reduce motor activity when measuring pressure and other parameters without anesthesia, animals were preliminarily trained by being planted into transparent cones for 2 days for 15 minutes. During the experiment, the following parameters were measured that characterize the work of the cardiovascular system: blood pressure (systolic, diastolic and mean), heart rate, blood flow and

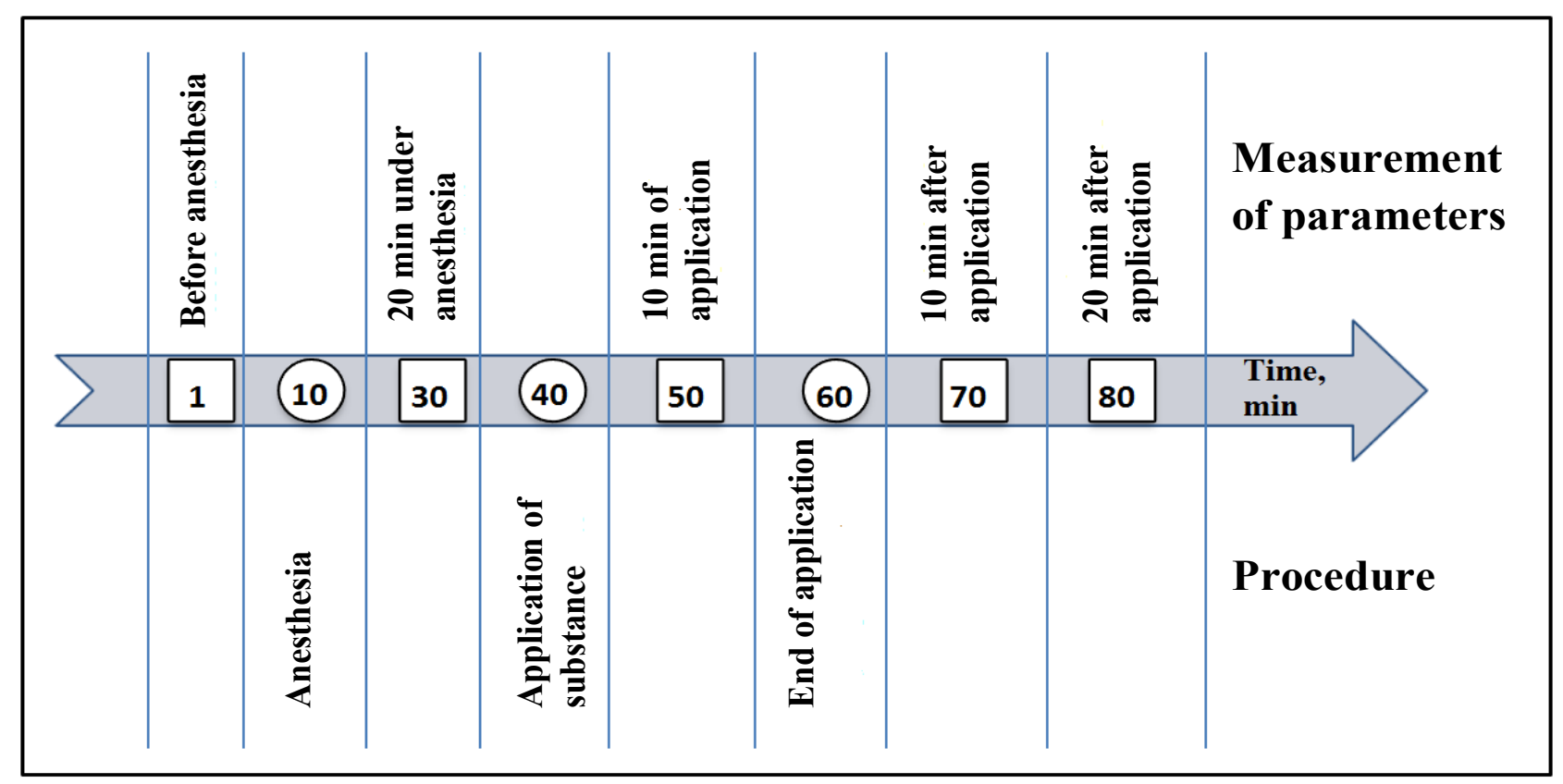

Figure 1: The course of the experiment. 
Table 1: Parameters of cardio-vascular system before and under anesthesia in normotensive and hypertensive rats.

\begin{tabular}{|c|c|c|c|c|c|c|}
\hline \multirow[t]{2}{*}{ Conditions } & \multicolumn{3}{|c|}{ Arterial pressure, $\mathrm{mmHg}$} & \multirow[b]{2}{*}{ Hart rate } & \multirow[b]{2}{*}{ Blood flow, $\mathrm{ml} / \mathrm{min}$} & \multirow[b]{2}{*}{$\begin{array}{l}\text { Tail blood } \\
\text { volume, } \mu \mathrm{l}\end{array}$} \\
\hline & Systolic & Diastolic & Mean & & & \\
\hline \multicolumn{7}{|l|}{ Normotensive $(n=20)$} \\
\hline Before anesthesia & $141.8 \pm 3.78$ & $102.0 \pm 2.98$ & $114.9 \pm 3.21$ & $354 \pm 6.3$ & $24.8 \pm 1.03$ & $97.8 \pm 5.46$ \\
\hline Under anesthesia - 20 min & $120.5 \pm 3.23^{* *}$ & $83.6 \pm 2.69^{* *}$ & $95.6 \pm 2.81^{\star *}$ & $425 \pm 15.3^{\star \star}$ & $18.7 \pm 1.37$ & $68.5 \pm 5.28^{*}$ \\
\hline \multicolumn{7}{|l|}{ Hypertensive $(n=24)$} \\
\hline Before anesthesia & $165.8 \pm 2.95$ & $124.0 \pm 2.77$ & $137.6 \pm 2.80$ & $371 \pm 11.2$ & $21.3 \pm 0.70$ & $86.3 \pm 3.00$ \\
\hline Under anesthesia - 20 min & $126.4 \pm 4.86^{* * *}$ & $87.6 \pm 3.77^{* * *}$ & $100.2 \pm 4.09^{* * *}$ & $383.2 \pm 9.73$ & $18.3 \pm 0.92^{*}$ & $73.9 \pm 4.23^{*}$ \\
\hline
\end{tabular}

Significant difference between the parameters before and at 20 minutes under of anesthesia: ${ }^{* * *}-\mathrm{P}<0.001 ;{ }^{* *}-\mathrm{P}<0.01 ;{ }^{*}-\mathrm{P}$ $<0.05$.

tail blood volume.

Statistical data processing was performed using Student's t-test for group comparison. Results are presented as $M \pm m$. The number of animals in each experimental group was at least 10 .

\section{Results}

\section{Introduction to anesthesia}

Initially, before anesthesia, diastolic and systolic pressure was higher in hypertensive animals, while heart rate, blood flow and tail blood volume did not significantly differ from similar parameters in normotensive animals (Table 1). 20 minutes after the introduction of anesthesia, a drop in blood pressure occurred in all animals, however, in hypertensive animals this drop was more pronounced $41 \pm 5.1 \mathrm{mmHg}$ (by $25 \%$ ) versus 21 $\pm 4.3 \mathrm{mmHg}$ (by $15 \%)$ in normotensive ones $(P<0.05)$; while tail blood volume decreased in hypertensive rats by $14 \%$ and in normotensive ones by $30 \%$. So that normo- and hypertensive animals in the state of anesthesia did not differ significantly in terms of blood pressure, blood flow and tail blood volume. Under anesthesia, an increase in heart rate was observed only in normotensive animals (Table 1).

\section{Recovery from anesthesia}

Recovery from anesthesia in control animals at the application of distilled water occurred differently in normal and hypertensive animals (Figure 2, light bars). In normotensive animals, systolic pressure increased slowly (the mean rate of systolic pressure rise at water application was $0.3 \pm 0.15 \mathrm{mmHg} / \mathrm{min}$ ), whereas in hypertensive animals pressure increased almost 5 times faster $-1.4 \pm 0.19 \mathrm{mmHg} / \mathrm{min}(P<0.01)$. Changes in diastolic and mean pressure were similar to those in systolic pressure. Tail blood volume increased in normotensive animals more rapidly than in hypertensive ones, and the mean rate of its increase was $1.3 \pm 0.19 \mu \mathrm{l} / \mathrm{min}$ and $0.4 \pm 0.14 \mu \mathrm{l} / \mathrm{min}$, respectively, $P<0.05$. The rise in blood flow was also more rapid in normotensives $(0.3$ $\left.\pm 0.05 \mathrm{ml} / \mathrm{min}^{2}\right)$ compared to hypertensives $(0.1 \pm 0.05$ $\left.\mathrm{ml} / \mathrm{min}^{2}\right) ; \mathrm{P}<0.05$. Heart rate decreased in normoten- sives $(-1.2 \pm 0.42$ beats $/ \mathrm{min})$ and increased in hypertensives ( $1.5 \pm 0.39$ beats $/ \mathrm{min})$.

\section{Effect of $1 \%$ menthol}

Effect of $1 \%$ menthol application on pressure and blood flow parameters when recovering from anesthesia was observed in both normotensive and hypertensive animals. Menthol accelerated the increase in pressure in animals of both groups, but this acceleration was expressed differently. In normotensive rats under the influence of menthol, the 3 times rise of arterial pressure was observed (Figure 2, top). This increase was registered at the $10^{\text {th }}$ minute of menthol application, as well as 10 and 20 minutes after the end of application. The mean rate of the arterial pressure rise was $0.3 \pm$ $0.15 \mathrm{mmHg} / \mathrm{min}$ at water and $0.9 \pm 0.10 \mathrm{mmHg} / \mathrm{min}$ at menthol application, $\mathrm{P}<0.05$, i.e. the rate of pressure rise at menthol application increased by 3 times in normotensives.

In hypertensive ones the rise in pressure when recovering from anesthesia under the influence of menthol did not change during the first 10 minutes of application, increased significantly 1.7 times 10 minutes after the end of the application and did not change 20 minutes after application (Figure 2, bottom). The rate of the arterial pressure increase 10 minutes after the end of the application was $1.2 \pm 0.21 \mathrm{mmHg} / \mathrm{min}$ at water and $2.1 \pm 0.26 \mathrm{mmHg} / \mathrm{min}$ at menthol application, $\mathrm{P}$ $<0.05$, i.e. in hypertensives, the rate of pressure rise when using menthol increased only by 1.7 times and was observed for a shorter time (only during the first 10 minutes). So, hypertensives were less sensitive to menthol in context of arterial pressure rise.

The diastolic and mean pressure in both groups of animals changed under the influence of menthol in a similar way as systolic. The pulse pressure did not change and was $39 \pm 1.1$ and $42 \pm 1.5 \mathrm{mmHg}$ in both groups of animals.

The influence of menthol on the heart rate was observed in normotensives. An increase in heart rate under anesthesia was observed only in normotensive animals and the recovery of this parameter was different at wa- 


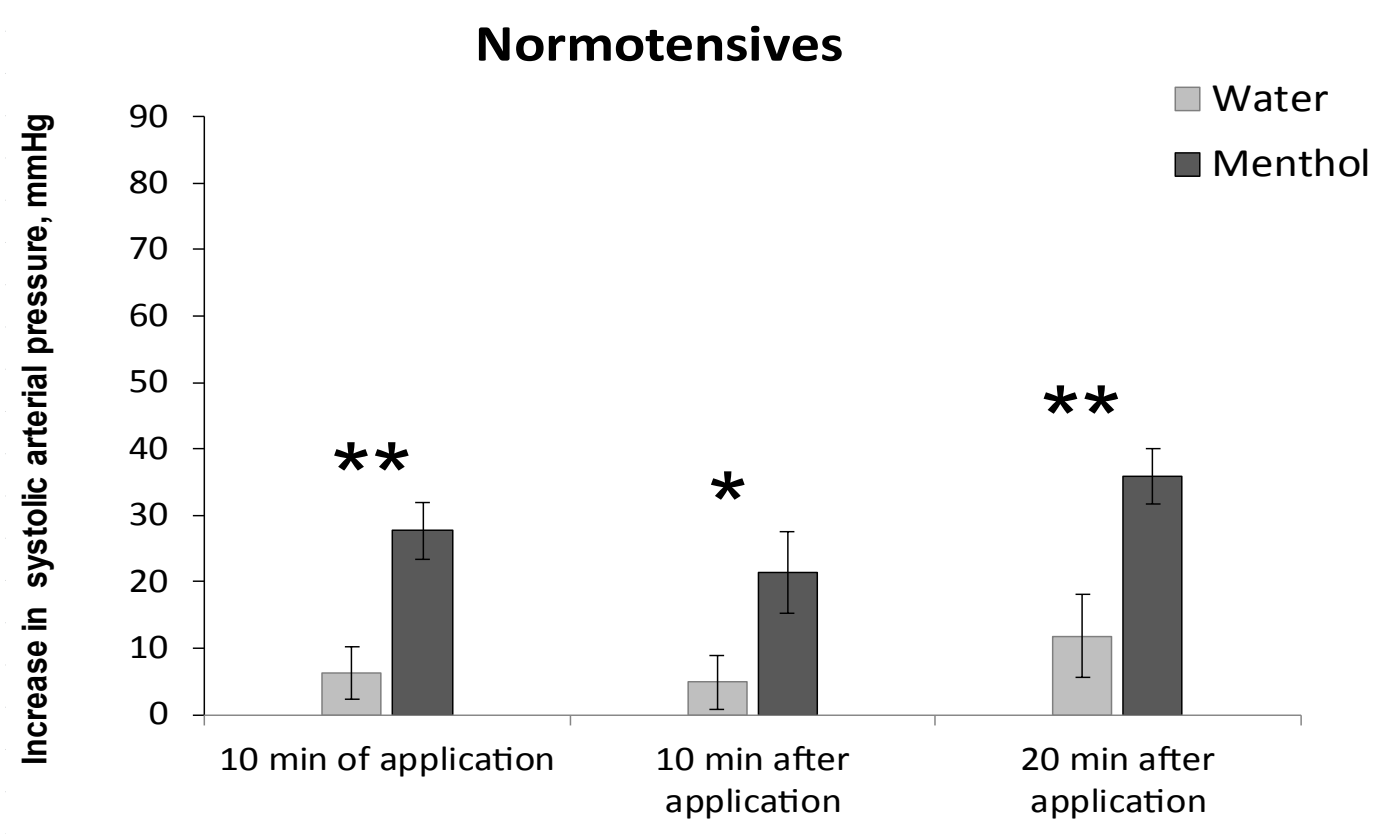

\section{Hypertensives}

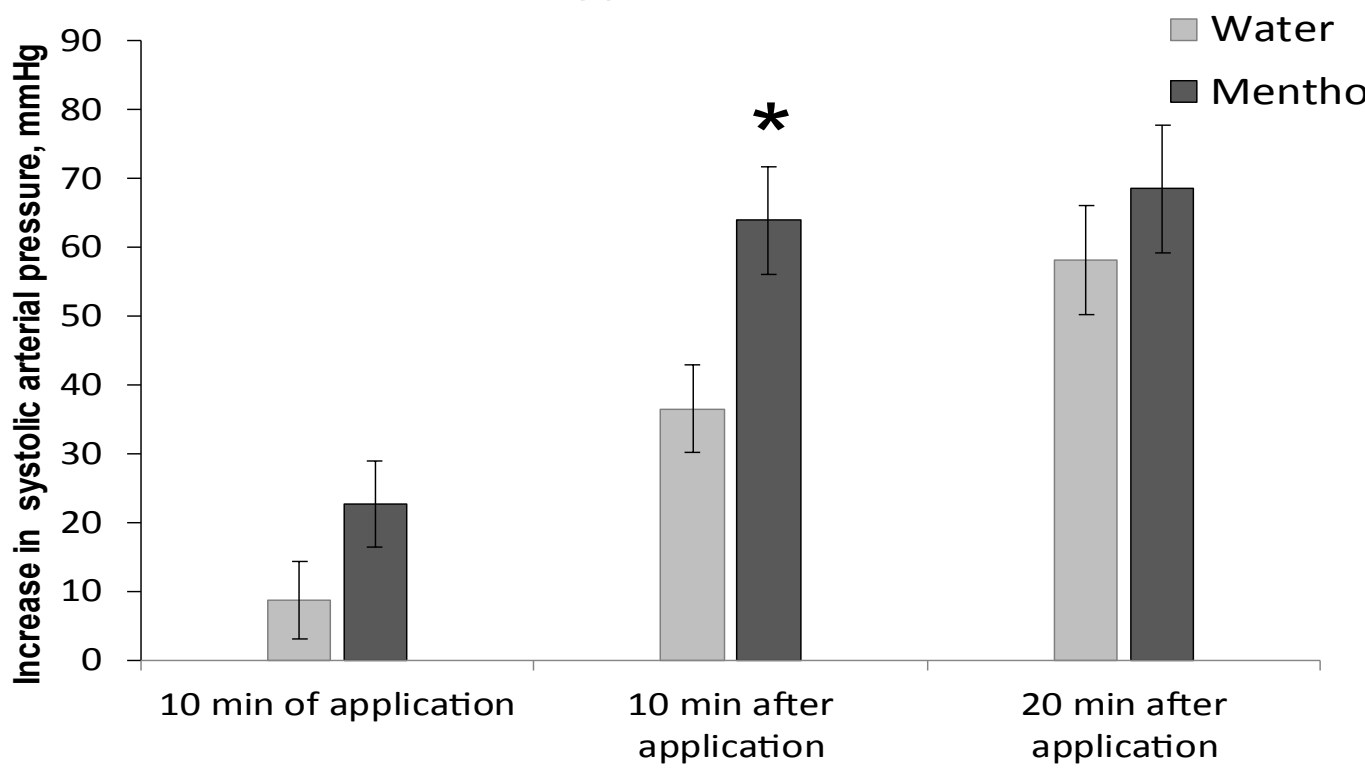

Figure 2: The increase in arterial systolic pressure when recovering from anesthesia in normotensive (top) and hypertensive (bottom) rats. Application of water - light bars, menthol - dark bars. Registration time is the $10^{\text {th }}$ minute of the application, the $10^{\text {th }}$ and $20^{\text {th }}$ minutes after the end of the substance application. Significant difference between the parameters at water and menthol application: ${ }^{* *}-\mathrm{P}<0.01$; $^{*}-\mathrm{P}<0.05$.

ter and menthol application. 20 minutes after menthol application the decrease in heart rate was significantly stronger under the menthol (105 \pm 21.3 beats $/ \mathrm{min}$ ) compared to water application ( $47 \pm 16.9$ beats $/ \mathrm{min}$ ), $\mathrm{P}<0.05$. When analyzing changes in heart rate in hypertensive animals, no regular changes were observed under the influence of menthol.

An increase in tail blood volume (i.e. in the caudal artery) when the animals recovered from anesthesia, as it can be seen in Figure 3, was significantly higher in normotensive rats compared to hypertensive ones at all times of measurement, both in animals with water application and the menthol application, $(P<0.01)$. In normotensives the significant effect of menthol on tail blood volume was observed during the first 10 minutes of application and at the $20^{\text {th }}$ minute after the end of application (Figure 3, top), the increase in tail blood volume was $80-60 \%$ higher under menthol than in animals when water was applied $(P<0.05)$. In hypertensives the effect of menthol on tail blood volume was not observed (Figure 3, bottom).

\section{Discussion}

So, under the influence of anesthesia, blood pressure decreases in both normo- and hypertensive animals. Since in hypertensive rats, this decrease is more pronounced, in the state of anesthesia, their blood pressure does not significantly differ from that of normotensive animals. Along with a decrease in pressure, the blood volume in the caudal artery also decreases, 

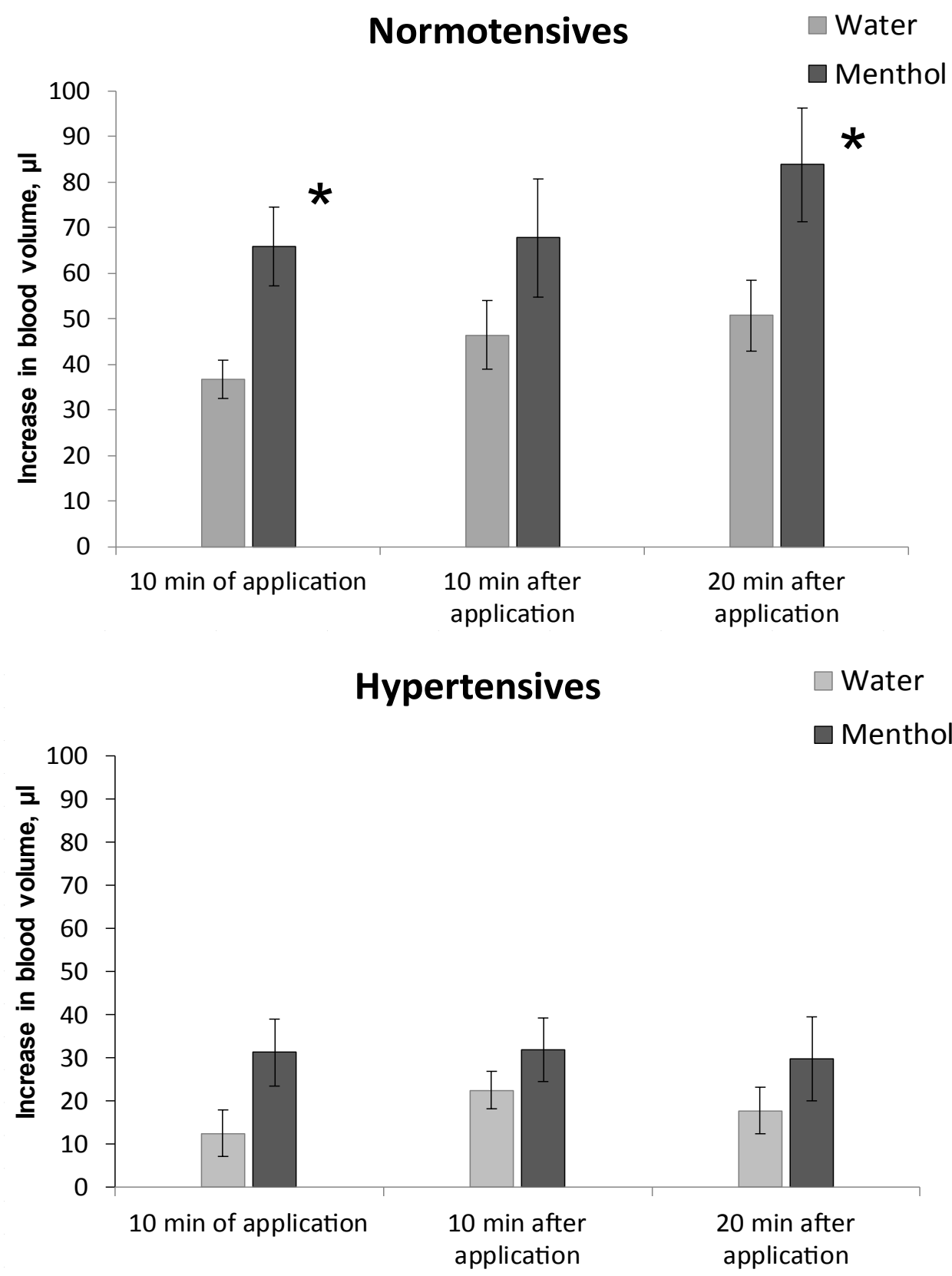

Figure 3: The increase in tail blood volume when recovering from anesthesia in normotensive (top) and hypertensive (bottom) rats. Application of water - light bars, menthol - dark bars. Registration time is the $10^{\text {th }}$ minute of the application, the $10^{\text {th }}$ and $20^{\text {th }}$ minutes after the end of the substance application. Significant difference between the parameters at water and menthol application: * $-\mathrm{P}<0.05$.

but a $15 \%$ decrease in pressure in normotensive animals is accompanied by a decrease in blood volume by $30 \%$, while in hypertensive animals a greater decrease in pressure (by $25 \%$ ) is accompanied by a smaller change in blood volume, only by $14 \%$. This may indicate a change in the dependence of blood volume on the level of blood pressure in hypertensive animals.

At the recovery from anesthesia, there is a gradual increase in blood pressure and tail blood volume in animals of both lines. An increase in pressure in hypertensive animals occurs faster and reaches higher values than in normotensive ones, while an increase in blood volume, on the contrary, in hypertensive animals is much lower than in normotensive ones.
The role of the TRPM8 ion channel in the regulation of blood pressure is clearly evident in normotensive animals. The activation of the peripheral cold-sensitive TRPM8 ion channel by its agonist menthol accelerates and increases the rise in blood pressure when animals recover from anesthesia. A significant increase in the rise of blood pressure is observed during the period of menthol application as well as 10 and 20 minutes after the end of menthol application. Hypertensive animals, unlike normotensive ones, have a weaker and shorter response to the activation of the TRPM 8 ion channel. A rise in arterial pressure in them appears only for a short time on the $10^{\text {th }}$ minute after the end of menthol application, but neither during menthol application, nor 20 minutes after the end of menthol application. 
The data obtained indicate, firstly, the involvement of the TRPM8 ion channel in the regulation of arterial blood pressure and blood volume (Figure 2 and Figure 3 ), and, secondly, a weaker contribution of this ion channel to regulation of these parameters in animals with hereditary stress-induced arterial hypertension. The latter is consistent with our earlier data on the two-fold decrease in the expression of the TRPM8 ion channel gene in these hypertensive animals (Voronova, et al. 2015). So, less expression of the Trpm8 gene associated with less sensitivity to menthol in context of arterial pressure rise.

The TRPM8 ion channel is cold-sensitive and participates in the regulation of the body's response to cold [12-16]. Our previous studies have shown that activation of the peripheral TRPM 8 ion channel reduces thresholds, i.e. accelerates the initiation, and enhances the value thermoregulatory response to cold [12]. The involvement of the sympathetic nervous system in the body's response to cold is well known. Therefore, it can be assumed that an increase in arterial blood pressure observed in the present study under the influence of the activation of the cold-sensitive TRPM 8 ion channel can be mediated by its influence on the activity of the sympathetic nervous system.

It should be noted that the question on the effect of cold on arterial blood pressure has long attracted the attention of researchers. However, the existing data on this issue are ambiguous. Some researchers state that there is an increase in arterial blood pressure under the action of cold [17-20] while others do not note such an effect $[21,22]$. According to our data obtained in the present and last studies, this may be due, in particular, to different expression of the TRPM8 ion channel gene. Previously obtained data on the association of cold sensitivity in people with the rs 11562975 polymorphism of the TRPM8 ion channel gene [23] suggest that the response of arterial pressure to cold in humans may also depend on the polymorphism and expression of the Trpm8 gene.

Thus, based on the results of the present and previous studies, it can be assumed that the TRPM 8 ion channel contributes to the regulation of arterial pressure, causing its increase. This contribution depends on the level of gene expression of this ion channel. Reducing the expression of the Trpm 8 gene in animals with hereditary stress-induced hypertension weakens the response of blood pressure to the activation of the TRPM 8 ion channel by its agonist menthol. It is possible that a decrease in the expression of the Trpm 8 gene is a compensatory protection in arterial hypertension.

\section{Conflict of Interests}

The authors declare that there is no conflict of interests regarding the publication of this manuscript.

\section{Acknowledgement}

The work was performed in the frame of Basic Research Project of the Russian Federation No. 05382014-0010. The authors declare no competing financial interests.

\section{References}

1. Voronova IP, Tuzhikova AA, Markel AL, Kozyreva TV (2015) Inherited stress-induced hypertension is associated with altered gene expression of thermosensitive TRP ion channels in hypothalamus. J Exp Integr Med 5: 149-156.

2. Sun J, Yang T, Wang P, Ma S, Zhu Z, et al. (2014) Activation of cold-sensing transient receptor potential melastatin subtype 8 antagonizes vasoconstriction and hypertension through attenuating RhoA/Rho kinase pathway. Hypertension 63: 1354-1363.

3. Craighead DH, Alexander LM (2016) Topical menthol increases cutaneous blood flow. Microvasc Res 107: 39-45.

4. Craighead DH, Alexander LM (2017) Menthol-induced cutaneous vasodilation is preserved in essential hypertensive men and women. Am J Hypertens 30: 11561162.

5. Ragan BG, AJ Nelson, JH Foreman, GW Bell, GA Iwamoto (2004) Effect of menthol-based analgesic balm on pressor responses evoked muscle afferents in cats. Am J Vet Res 65: 1204-1210.

6. Johnson CD, Melanaphy D, Purse A, Stokesberry SA, Dickson P, et al. (2009) Transient receptor potential melastatin 8 channel involvement in the regulation of vascular tone. Am J Physiol Heart Circ Physiol 296: $\mathrm{H} 1868-\mathrm{H} 1877$.

7. Olive JL, Hollis B, Mattson E, Topp R (2010) Vascular conductance is reduced after menthol or cold application. Clin J Sport Med 20: 372-376.

8. Markel AL (1992) Development of a new strain of rats with inherited stress-induced arterial hypertension. In: Sassard J, Genetic Hypertension 28. Colloque INSERM, John Libbey Eurotext Ltd, 405-407.

9. Kobayashi K, Fukuoka T, Obata K, Yamanaka H, Dai Y (2005) Distinct expression of TRPM8, TRPA1, and TRPV1 mRNAs in rat primary afferent neurons with adelta/c-fibers and co-localization with TRK receptors. J Comp Neurol 493: 596-606.

10. McCoy DD, Knowlton WM, McKemy DD (2011) Scraping through the ice: uncovering the role of TRPM8 in cold transduction. Am J Physiol Regul Integr Comp Physiol 300: 1278-1287.

11. Caterina MJ, Pang Z (2016) TRP channels in skin biology and patho-physiology. Pharmaceuticals (Basel) 9: E77.

12. Kozyreva TV, Kozaruk VP, Tkachenko E Ya, Khramova GM (2010) Agonist of TRPM8 channel, menthol, facilitates the initiation of thermoregulatory responses to external cooling. J Thermal Biology 35: 428-434.

13. Kozyreva TV, Voronova IP (2015) Involvement of neurogenomic regulation in maintenance of temperature homeostasis in the cold. Russian Journal of Genetics 5: 569-576.

14. Knowlton WM, Bifolck-Fisher A, Bautista DM, McKemy DD (2010) TRPM8, but not TRPA1, is required for neural and behavioral responses to acute noxious cold temperatures and cold mimetics in vivo. Pain 150: 340-350. 
15. Narender R Gavva, Carl Davis, Sonya G Lehto, Sara Rao, Weiya Wang, et al. (2012) Transient receptor potential melastatin 8 (TRPM8) channels are involved in body temperature regulation. Molecular Pain 8: 36-47.

16. Almeida MC, Hew-Butler T, Soriano RN, Rao S, Wang W, et al. (2012) Pharmacological blockade of the cold receptor TRPM8 attenuates autonomic and behavioral cold defenses and decreases deep body temperature. J Neurosci 32: 2086-2099.

17. Fregly MJ, Schechtman O (1994) Direct blood pressure measurements in rats during abrupt exposure to, and removal from, cold air. Proc Soc Exp Biol Med 205: 119123.

18. Arjamaa O, Mäkinen $T$, Turunen L, Huttunen $P$, Leppäluoto $J$, et al. (2001) Blood pressure and endocrine responses of healthy subjects in cold pressor test after acutely increased dietary sodium intake. J Physiol Anthropol Appl Human Sci 20: 207-212.
19. Greif R, Lacini S, Rajek A, Doufas A, Sessler D (2003) Blood pressure response to thermoregulatory vasoconstriction during isoflurane and desflurane anesthesia. Acta Anaesthesiol Scand 47: 847-852.

20. Kuo TB, Hong CH, Hsieh IT, Lee GS, Yang CC (2014) Effects of cold exposure on autonomic changes during the last rapid eye movement sleep transition and morning blood pressure surge in humans. Sleep Med 15: 986-997.

21. Wagner JA, Horvath SM (1985) Cardiovascular reactions to cold exposures differ with age and gender. J Appl Physiol 58: 187-192.

22. Halonen JI, Zanobetti A, Sparrow D, Vokonas PS, Schwartz J (2011) Relationship between outdoor temperature and blood pressure. Occup Environ Med 68: 296-301.

23. Kozyreva TV, Tkachenko E Ya, Potapova TA, Voevoda MI (2014) Respiratory system response to local cooling in subjects with single nucleotide polymorphism rs11562975 of the trpm8 temperature-sensitive ion channel gene. Human Physiology 40: 197-200. 